\title{
Multiple Antihypertensive Therapy in Nephrology Practice
}

\section{Yao Kouame Hubert*, Doro Arouna, Guehi Monlet Cyr, Konan Serge Didier, Gnionsahe Daze Appolinaire}

Department of Nephrology, Treichville Teaching Hospital, Abidjan, Côte d'Ivoire

Email: ${ }^{*}$ aohubert@yahoo.fr

How to cite this paper: Hubert, Y.K., Arouna, D., Cyr, G.M., Didier, K.S. and Appolinaire, G.D. (2017) Multiple Antihypertensive Therapy in Nephrology Practice. Open Journal of Nephrology, 7, 80-93. https://doi.org/10.4236/ojneph.2017.73010

Received: August 10, 2017

Accepted: September 25, 2017

Published: September 28, 2017

Copyright (๑) 2017 by authors and Scientific Research Publishing Inc. This work is licensed under the Creative Commons Attribution International License (CC BY 4.0).

http://creativecommons.org/licenses/by/4.0/

\section{(c) (i) Open Access}

\begin{abstract}
Introduction: Hypertension (HT) can be the cause or consequence of chronic kidney disease. Its management often requires a multiple therapy due to its severity. Objective: To describe the profile of patients receiving a multiple antihypertensive therapy in nephrology practice. Materials and Methods: This was a prospective, descriptive study conducted in the department of Nephrology, Yopougon Teaching Hospital, from January 1 to October 31, 2016. We included all patients admitted to this department who had received at least three antihypertensive drugs. Results: Out of a total of 625 hypertensive patients admitted over the study period, we included 120 patients on multiple therapy, i.e. a $19 \%$ prevalence. HT was essential in $60 \%$ of cases, secondary to chronic glomerulonephritis (CGN) in $25 \%$, to diabetes in $13.3 \%$ and to polycystic kidney disease (PKD) in 1.7\%. The therapy consisted of the combination of 3 antihypertensive drugs in $36.7 \%$ of cases, 4 drugs in $49.2 \%$ and 5 drugs in $4.2 \%$. The antihypertensive classes used were Calcium channel blockers (CCB) in $99.2 \%$ of cases, Diuretics (D) in $87.5 \%$, Angiotensin Converting Enzyme Inhibitors (ACEI) in 70\%, Centrally acting medication $(\mathrm{C})$ in 66.7\%, Angiotensin Receptor Blockers (ARB) in $25.8 \%$ and Beta-blockers ( $\beta$-) in $6.7 \%$. The main combinations were $\mathrm{CCB}+\mathrm{D}+\mathrm{ACEI}+\mathrm{C}$ in $34.2 \%$ of cases, $\mathrm{CCB}+\mathrm{D}+\mathrm{ACEI}$ in $23.3 \%$, and $\mathrm{CCB}+\mathrm{D}+\mathrm{ARB}+\mathrm{C}$ in $12.5 \%$. The combinations of antihypertensive drugs varied according to the cause of HT with a non-significant difference. Patient outcome was characterized by normal blood pressure in $64.2 \%$ of cases and normal renal function in $13.3 \%$. The mortality rate was $17.5 \%$. In multivariate analysis, stage 5 renal disease $(\mathrm{p}=$ $0.001)$, hypertensive retinopathy $(\mathrm{p}=0.04)$ and hemoglobin level $<8 \mathrm{~g} / \mathrm{dl}(\mathrm{p}=$ $0.039)$ were associated with mortality. Conclusion: Multiple antihypertensive therapy, which is common in nephrology, is related to the severity of HT and not to its cause. We still use centrally acting drugs in combination with the other recommended classes, so as to achieve the target blood pressure.
\end{abstract}




\section{Keywords}

Hypertension, Multiple Therapy, Nephrology

\section{Introduction}

Hypertension (HT) is the first chronic disease worldwide affecting approximately one billion people. Seven to eight million deaths were related to HT in 2011 globally [1]. The kidneys constitute, besides the heart and brain, one of the target organs of untreated or insufficiently treated hypertension.

The issue of hypertension in nephrology is fundamental. Indeed, it is one of the main reasons for dialysis worldwide. In the West, it is the second leading cause of chronic end-stage renal disease (ESRD) after diabetes. Thus, in the French REIN 2012 registry, the proportion of ESRD related to HT was $25.1 \%$ [2]. In Africa, HT is known to be the leading cause of ESRD especially in sub-Saharan Africa. In Côte d'Ivoire, HT is the major risk factor for chronic end-stage renal disease [3].

Renal diseases themselves can cause hypertension. In this case, the latter is a sign of these renal diseases. This is actually a vicious circle in which hypertension and renal disease negatively interact [4]. Finally, in our context, the hydrosodic overload due to insufficient dialysis, often due to the dialysis strategy of two sessions per week in most patients, may contribute to the occurrence or aggravation of hypertension in chronic dialysis patients. HT in nephrology can thus be either the cause of chronic kidney disease, the consequence of that one, or a factor for progression to chronic ESRD. Its management often requires a multiple therapy due to its severity. But we do not know if patients with secondary HT require more antihypertensive drugs than patients with essential HT to control their blood pressure. Our study aims to describe the profile of patients on multiple antihypertensive therapy in nephrology practice.

\section{Methods}

\subsection{Study Type and Population}

This is a prospective, descriptive study conducted in the Department of Nephrology, Yopougon Teaching Hospital, from January 1 to October 31, 2016. Any patient aged 18 or older, receiving a once-daily combination of at least three antihypertensive drugs and admitted to this department, was included. Patients who were treated with one or two drugs, on dialysis prior to admission or with incomplete follow-up were not included.

\subsection{Variables}

For each patient included, the following data were collected using a standardized form: socio-demographic data (age, gender, occupation, marital status and education level), anamnestic data (the concepts of edema, hypertension, diabetes, 
chronic kidney disease, tobacco, alcohol consumption, inherited disease and past medical history), clinical data (reason for admission, blood pressure upon admission, weight, height, presence of lower-limb edema, acute pulmonary edema, state of consciousness, hydration status, diuresis, fundoscopic examination and urine strip test), laboratory data (serum creatinine, plasma urea, calcium, phosphoremia, 24-hour urine protein, hemoglobin, mean corpuscular volume, platelet count and cytobacteriological examination of urine), imaging data (teleheart, renal ultrasound and electrocardiogram), treatment data (antihypertensive therapy: class, molecule, combinations, and hemodialysis), and evolutionary data (control of BP, renal disease stage, chronic dialysis, and death).

Each included patient benefited from a six-month clinical and biological follow-up upon admission, at day 15, month (M)1, M2, M3 and M6. The primary endpoint was death and the secondary endpoints were blood pressure at 6 months and the development of renal function.

\subsection{Operational Definitions}

Blood pressure was measured and classified as per World Health Organization (WHO) guidelines [5], using a digital sphygmomanometer on the right arm of seated participant after at least five minutes of rest. Hypertension was defined as systolic blood pressure $\geq 140 \mathrm{mmHg}$ and/or diastolic blood pressure $\geq 90 \mathrm{mmHg}$ or lower than $140 / 90 \mathrm{mmHg}$ in patients on antihypertensive therapy [6].

Diabetes is defined as fasting blood glucose higher than $1.26 \mathrm{~g} / \mathrm{l}$ or normal blood glucose in any participant on anti-diabetic therapy [7].

The effects of hypertension on the heart were assessed by electrocardiography (ECG) detection of left ventricular hypertrophy (LVH). The ocular effects of hypertension and its severity were assessed using the fundoscopic examination. The KIRKENDALL classification was used for hypertensive retinopathy stages.

Renal function was assessed using the MDRD equation. Renal failure was defined as a glomerular filtration rate (GFR) below $60 \mathrm{ml} / \mathrm{min}$ for $1.73 \mathrm{~m}^{2}$ and classified according to the KDOQI guidelines [8]. The chronic stage was confirmed in case of renal disease that had been persistent for more than 3 months and/or associated hypocalcemia and/or normochromic normocytic anemia.

The etiological investigation of hypertension was based on clinical and paraclinical arguments. Thus, glomerulonephritis was diagnosed in the presence of proteinuria greater than or equal to $1.5 \mathrm{~g} / 24 \mathrm{hrs}$ or proteinuria associated with hematuria [9]. Hypertension occurring after type 2 diabetes, without positive albuminuria test, was confirmed as being secondary to diabetes [10]. Polycystic kidney disease was diagnosed in the presence of multiple renal cysts with enlarged kidneys [11].

Anemia was confirmed in any patient with a hemoglobin level below $12 \mathrm{~g} / \mathrm{dl}$, and considered severe when hemoglobin level was below $8 \mathrm{~g} / \mathrm{dl}$. No patient had a kidney biopsy.

Any patient receiving at least three antihypertensive drugs was considered on 
multiple antihypertensive therapy. This was initiated due to the severity of hypertension. All patients received three antihypertensive drugs combined with hygiene and dietary measures at inclusion. The choice of combined molecules was dependent on the initial clinical condition. Dosage adjustment or the addition of another antihypertensive drug depended on the blood pressure during subsequent follow-up.

\subsection{Statistical Analysis}

Data were entered into an Excel database and analyzed using the SPSS software version 22. We first carried out a descriptive analysis. Quantitative variables were described as mean when their distribution was normal otherwise, as median. In univariate analysis, the proportions of qualitative variables were compared according to age groups, across known or unknown hypertensive patients, and across patients who died or not, using a Chi-square test or a Fisher's exact test. Relative quantitative variables were transformed into categorical variables according to pathological norms. Kaplan Meier curves were built for survival analysis. Cox regression analysis was used to identify independent predictors of mortality. We also performed a logistic regression to identify factors associated with progression of renal disease. Measures of association were calculated using $95 \%$ confidence intervals. $\mathrm{P}<0.05$ defined the level of statistical significance.

\subsection{Ethical Considerations}

Prior to inclusion, all patients gave verbal and written consent to participate in this study. Anonymity and confidentiality of data collected were maintained by assigning an identification number to each patient's medical record.

\section{Results}

Over the study period, 120 cases of multiple antihypertensive therapy with a complete 6-month follow-up were included out of a total of 625 hypertensive patients, i.e. a $19 \%$ prevalence. The mean age was $45 \pm 16$ years with a range of 18 to 80 years. The proportion of subjects aged 65 or older was $11.1 \%$. We observed a male predominance with a sex ratio of 1.45 .

Patients were mostly unemployed $(n=45 ; 37.5 \%)$, traders $(n=25 ; 20.8 \%)$ and working in the field of agriculture $(\mathrm{n}=17 ; 14.2 \%) .77 .5 \%$ were known to be hypertensive before admission, with an average duration of HT progression being $6.35 \pm 4$ years (range of 6 months to 35 years). They were followed up by a general practitioner (31.7\%), a registered nurse (15.8\%), and a cardiologist $(4.2 \%) ; 38.7 \%$ of them were not followed up. Prior to inclusion, the antihypertensive drugs used were Calcium channel blockers (CCB) in $37.5 \%$ of cases, Angiotensin-converting enzyme inhibitors (ACEI) in $17.4 \%$, Diuretics (D) in $8.3 \%$, and Centrally acting medication (C) in 5.8\%, in combination or not (Figure 1).

The main reasons for admission were lower limb edema (75.8\%), headache (59.2\%), and dyspnea (44.2\%). In addition, almost all patients (96.7\%) were 


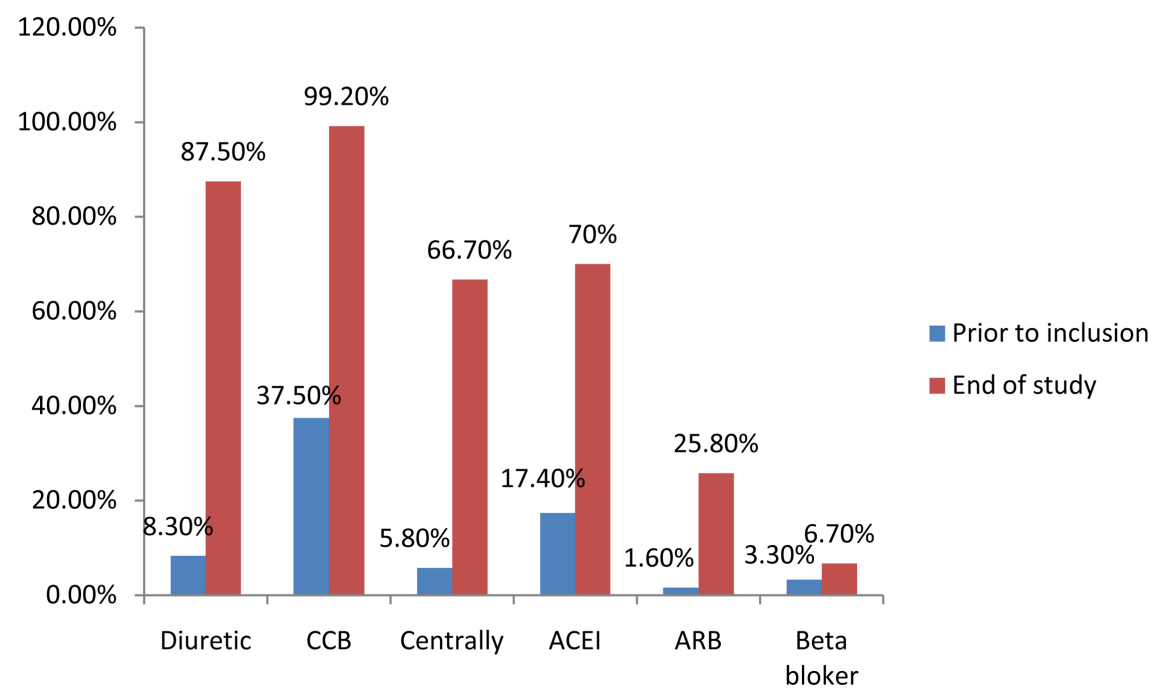

Figure 1. Class of antihypertensive drugs prior to inclusion and at the end of the study.

referred to the nephrology department for impaired renal function.

At baseline, 83.3\% of cases had grade $3 \mathrm{HT}, 13.3 \%$ had grade $2 \mathrm{HT}$ and $1.6 \%$ had grade $1 \mathrm{HT}$. According to the Kirkendall classification, $44.2 \%$ of cases had stage 3 hypertensive retinopathy, $20 \%$ had stage 2 hypertensive retinopathy and $5 \%$ had stage 1 hypertensive retinopathy. Left ventricular hypertrophy (LVH) was reported in $83.3 \%$ of cases (Table 1 ).

Renal failure was chronic in $78.3 \%$ of cases. $50 \%$ had stage 5 renal failure, $26.7 \%$ had stage 4 renal failure, $20 \%$ had stage 3 renal failure, $0.8 \%$ had stage 2 renal failure and $0.8 \%$ had stage 1 renal failure. The hemoglobin level was lower than $12 \mathrm{~g} / \mathrm{dl}$ in $78.3 \%$ of cases, of which $25 \%$ had lower than $8 \mathrm{~g} / \mathrm{dl}$ (Table 1 ).

With regards to the etiologies, HT was essential in $60 \%$ of cases, secondary to chronic glomerulonephritis (CGN) in $25 \%$, to diabetes in $13.3 \%$ and to polycystic kidney disease (PKD) in 1.7\% (Table 1).

When comparing age groups, we observed that the proportion of known HT significantly increased with older age $(\mathrm{p}=0.035)$. Conversely, the proportions of grade 3 HT $(\mathrm{p}=0.009)$ and CGN $(\mathrm{p}=0.0001)$ decreased with older age (Table 1). Patients not known to be hypertensive before the current episode were aged, on average, $37 \pm 12$ years versus $47 \pm 14$ years for known hypertensive patients $(\mathrm{p}=0.001)$. The proportion of HT due to CGN was higher in this group with a significant difference $[\mathrm{OR}=2.06 ; 95 \% \mathrm{CI}=1.08-3.93 ; \mathrm{p}=0.03]$ (Table 2).

The therapy consisted of the combination of 3 drugs in $36.7 \%$ of cases, 4 drugs in $49.2 \%$ and 5 drugs in $4.2 \%$. The antihypertensive classes used were Calcium channel blockers (CCB) in $99.2 \%$ of cases, Diuretics (D) in $87.5 \%$, Angiotensin converting enzyme (ACEI) inhibitors in $70 \%$, centrally acting medication $(C)$ in 66.7\%, Angiotensin receptor blockers (ARB) in $25.8 \%$ and Beta-blockers ( $\beta$-) in $6.7 \%$ (Table 1). The main combinations were CCB + D + ACEI + C in $34.2 \%$ of cases, $\mathrm{CCB}+\mathrm{D}+\mathrm{ACEI}$ in $23.3 \%$, and $\mathrm{CCB}+\mathrm{D}+\mathrm{ARB}+\mathrm{C}$ in $12.5 \%$ (Table 1). The combinations of antihypertensive drugs varied according to the cause of HT 
Table 1. General characteristics of patients.

\begin{tabular}{|c|c|c|c|c|c|}
\hline & $\begin{array}{c}\text { Total } \\
(\mathrm{n}=120)\end{array}$ & $\begin{array}{l}<35 \text { years } \\
(n=32)\end{array}$ & $\begin{array}{c}{[35-65] \text { years }} \\
(\mathrm{n}=74)\end{array}$ & $\begin{array}{c}\geq 65 \text { years } \\
(n=14)\end{array}$ & $P$ value \\
\hline Male & $59.2 \%(71 / 120)$ & $53.1 \%(17 / 32)$ & $60.8 \%(45 / 74)$ & $64.3 \%(9 / 14)$ & 0.69 \\
\hline Female & $40.8 \%(49 / 120)$ & $46.9 \%(15 / 32)$ & $39.2 \%(29 / 120)$ & $35.7 \%(5 / 14)$ & \\
\hline Known hypertension & $72.5 \%(93 / 120)$ & $65.6 \%(21 / 32)$ & $78.4 \%(58 / 74)$ & $100 \%(14 / 14)$ & 0.035 \\
\hline Diabetes & $16.7 \%(20 / 120)$ & $0 \%$ & $23 \%(17 / 74)$ & $21.4 \%(3 / 14)$ & 0.013 \\
\hline Tobacco & $24.2 \%(29 / 120)$ & $28.1 \%(9 / 32)$ & $27 \%(20 / 74)$ & $0 \%$ & 0.70 \\
\hline Obesity & $5.8 \%(7 / 120)$ & $0 \%$ & $6.8 \%(5 / 74)$ & $14.3 \%(2 / 14)$ & 0.14 \\
\hline \multicolumn{6}{|l|}{ Hypertension grade } \\
\hline Normal BP & $1.6 \%(2 / 120)$ & $0 \%$ & $1.4 \%(1 / 74)$ & $7.1 \%(1 / 14)$ & 0.05 \\
\hline Grade 1 Hypertension & $1.6 \%(2 / 120)$ & $0 \%$ & $2.7 \%(2 / 74)$ & $0 \%$ & 0.53 \\
\hline Grade 2 Hypertension & $13.3 \%(16 / 120)$ & $6.3 \%(2 / 32)$ & $12.2 \%(9 / 74)$ & $35.7 \%(5 / 14)$ & 0.023 \\
\hline Grade 3 Hypertension & $83.3 \%(100 / 120)$ & $93.8 \%(30 / 32)$ & $83.8 \%(62 / 74)$ & $57.1 \%(8 / 14)$ & 0.009 \\
\hline \multicolumn{6}{|l|}{ Renal disease stage } \\
\hline Normal & $1.7 \%(2 / 120)$ & $3.1 \%(1 / 32)$ & $1.4 \%(1 / 74)$ & $0 \%$ & 0.70 \\
\hline Stage 1 & $0.8 \%(1 / 120)$ & $0 \%$ & $1.4 \%(1 / 74)$ & $0 \%$ & 0.73 \\
\hline Stage 2 & $0.8 \%(1 / 120)$ & $0 \%$ & $1.4 \%(1 / 74)$ & $0 \%$ & 0.73 \\
\hline Stage 3 & $20 \%(24 / 120)$ & $28.1 \%(9 / 32)$ & $18.9 \%(14 / 74)$ & $7.1 \%(1 / 14)$ & 0.24 \\
\hline Stage 4 & $26.7 \%(32 / 120)$ & $9.4 \%(3 / 32)$ & $31.1 \%(23 / 74)$ & $42.9 \%(6 / 14)$ & 0.023 \\
\hline Stage 5 & $50 \%(60: 120)$ & $59.4 \%(19 / 32)$ & $45.9 \%(34 / 74)$ & $50 \%(7 / 14)$ & 0.44 \\
\hline \multicolumn{6}{|l|}{ Hemoglobin level $(\mathrm{g} / \mathrm{dl})$} \\
\hline$\geq 12$ & $21.7 \%(26 / 120)$ & $18.8 \%(6 / 32)$ & $24.3 \%(18 / 74)$ & $14.3 \%(2 / 14)$ & 0.63 \\
\hline$[8-12]$ & $53.3 \%(64 / 120)$ & $53.1 \%(17 / 32)$ & $50 \%(37 / 74)$ & $71.4 \%(10 / 14)$ & 0.33 \\
\hline$<8$ & $25 \%(30 / 120)$ & $28.1 \%(9 / 32)$ & $25.7 \%(19 / 74)$ & $14.3 \%(2 / 14)$ & 0.59 \\
\hline \multicolumn{6}{|l|}{ Fundoscopic exam } \\
\hline Normal & $30.8 \%(37 / 120)$ & $34.4 \%(11 / 32)$ & $32.4 \%(24 / 74)$ & $14.3 \%(2 / 14)$ & 0.35 \\
\hline Retinopathy 1 & $5 \%(6 / 120)$ & $3.1 \%(1 / 32)$ & $5.4 \%(4 / 74)$ & $7.1 \%(1 / 14)$ & 0.82 \\
\hline Retinopathy 2 & $20 \%(24 / 120)$ & $25 \%(8 / 32)$ & $16.2 \%(12 / 74)$ & $28.6 \%(4 / 14)$ & 0.40 \\
\hline Retinopathy 3 & $44.2 \%(53 / 120)$ & $37.5 \%(12 / 32)$ & $45.9 \%(34 / 74)$ & $50 \%(7 / 14)$ & 0.64 \\
\hline LVH & $83.3 \%(100 / 120)$ & $78.1 \%(25 / 32)$ & $83.8 \%(62 / 74)$ & $92.9 \%(13 / 14)$ & 0.46 \\
\hline \multicolumn{6}{|l|}{ Etiology of hypertension } \\
\hline Essential & $60 \%(72 / 120)$ & $46.9 \%(15 / 32)$ & $62.2 \%(46 / 74)$ & $78.6 \%(11 / 14)$ & 0.10 \\
\hline Chronic GN & $25 \%(30 / 120)$ & $53.1 \%(17 / 32)$ & $17.6 \%(13 / 74)$ & $0 \%$ & 0.0001 \\
\hline Diabetes & $13.3 \%(16 / 120)$ & $0 \%$ & $17.6 \%(13 / 74)$ & $21.4 \%(3 / 14)$ & 0.032 \\
\hline PKD & $1.7 \%(2 / 120)$ & $0 \%$ & $2.7 \%(2 / 74)$ & $0 \%$ & 0.53 \\
\hline \multicolumn{6}{|l|}{ Drug combination } \\
\hline $\mathrm{CCB}+\mathrm{D}+\mathrm{ACEI}+\mathrm{C}$ & $34.2 \%(41 / 120)$ & $46.9 \%(15 / 32)$ & $28.4 \%(21 / 74)$ & $35.7 \%(5 / 14)$ & 0.18 \\
\hline $\mathrm{CCB}+\mathrm{D}+\mathrm{ARB}+\mathrm{C}$ & $12.5 \%(15 / 120)$ & $25 \%(8 / 32)$ & $6.8 \%(5 / 74)$ & $14.3 \%(2 / 14)$ & 0.03 \\
\hline $\mathrm{CCB}+\mathrm{D}+\mathrm{ACEI}$ & $23.3 \%(28 / 120)$ & $18.8 \%(6 / 32)$ & $25.7 \%(19 / 74)$ & $21.4 \%(3 / 14)$ & 0.72 \\
\hline $\mathrm{CCB}+\mathrm{D}+\mathrm{ARB}$ & $10 \%(12 / 120)$ & $3.1 \%(1 / 32)$ & $12.2 \%(9 / 74)$ & $14.3 \%(2 / 14)$ & 0.30 \\
\hline Others & $20 \%(24 / 120)$ & $6.3 \%(2 / 32)$ & $27 \%(20 / 74)$ & $14.3 \%(2 / 14)$ & 0.42 \\
\hline \multicolumn{6}{|l|}{ Outcomes } \\
\hline Normal blood pressure & $64.2 \%(77 / 120)$ & $50 \%(16 / 32)$ & $70.3 \%(52 / 74)$ & $64.3 \%(9 / 14)$ & 0.136 \\
\hline Persistent hypertension & $18.3 \%(22 / 120)$ & $28.1 \%(9 / 32)$ & $16.2 \%(12 / 74)$ & $7.1 \%(1 / 14)$ & 0.179 \\
\hline Death & $17.5 \%(21 / 120)$ & $21.9 \%(7 / 32)$ & $13.5 \%(10 / 74)$ & $28.6 \%(4 / 14)$ & 0.29 \\
\hline
\end{tabular}

LVH = Left Ventricular Hypertrophy; GN = Glomerulonephritis; PKD = Polycystic Kidney Disease; CCB = Calcium Channel Blocker; D = Diuretic; ACEI = Angiotensin Converting Enzyme; $\mathrm{ARB}=$ Angiotensin receptor Blocker; $\mathrm{C}=$ Centrally acting medication. 
Table 2. Combinations of antihypertensive drugs according to causes of hypertension.

\begin{tabular}{cccccc}
\hline & Essential & Chronic GN & Diabetes & PKD & P value \\
\hline Number of drugs & & & & & \\
3 & $47.2 \%(34 / 72)$ & $43.3 \%(13 / 30)$ & $43.8 \%(7 / 16)$ & $100 \%(2 / 2)$ & 0.47 \\
4 & $51.4 \%(37 / 72)$ & $46.7 \%(14 / 30)$ & $50 \%(8 / 16)$ & - & 0.54 \\
5 & $1.4 \%(1 / 72)$ & $10 \%(3 / 30)$ & $6.3 \%(1 / 16)$ & - & 0.24 \\
Combination & & & & - & 0.76 \\
CCB + D + ACEI + C & $34.7 \%(25 / 72)$ & $33.3 \%(10 / 30)$ & $37.5 \%(6 / 16)$ & - & 0.82 \\
CCB + D + ARB + C & $11.1 \%(8 / 72)$ & $16.5 \%(5 / 30)$ & $12.5 \%(2 / 16)$ & - & 0.22 \\
CCB + D + ACEI & $19.4 \%(14 / 72)$ & $36.7 \%(11 / 30)$ & $18.8 \%(3 / 16)$ & - & 0.09 \\
CCB + D + ARB & $9.7 \%(7 / 72)$ & $3.3 \%(1 / 30)$ & $18.8 \%(3 / 16)$ & $50 \%(1 / 2)$ & 0.19 \\
\hline Others & $25 \%(18 / 72)$ & $10 \%(3 / 30)$ & $12.5 \%(3 / 16)$ & $50 \%(1 / 2)$ & \\
\hline
\end{tabular}

with a non-significant difference (Table 2). However, three out of five patients receiving a five-drug combination presented with HT secondary to CGN.

Patient outcome was characterized by normal blood pressure in $64.2 \%$ of cases, and persistent $\mathrm{HT}$ in $18.3 \%$ (including $13.3 \%$ with grade 1 and $5 \%$ with grade 2) (Table 1). The drug combinations that made it possible to achieve the target blood pressure were $\mathrm{CCB}+\mathrm{D}+\mathrm{ACEI}+\mathrm{C}(32.5 \%)$ and $\mathrm{CCB}+\mathrm{D}+\mathrm{ACEI}$ (24.7\%) (Table 3 ). Renal function was normal in $13.3 \%$ of cases. $2.5 \%$ of cases had stage 5 renal disease, $10 \%$ had stage 4 renal disease, $32.5 \%$ had stage 3 renal disease, and 3.3\% had stage 2 renal disease. Moreover, 19.2\% of patients were on chronic dialysis (stage 5D) (Figure 2). The factors associated with renal disease progression were stage 5 renal disease at inclusion $(\mathrm{OR}=14.52 ; 95 \% \mathrm{CI}=4.08$ $21.65 ; \mathrm{p}=0.0001)$, persistent hypertension $(\mathrm{OR}=12.85 ; 95 \% \mathrm{CI}=4.45-17.13 ; \mathrm{p}=$ $0.0001)$ and hemoglobin level below $12 \mathrm{~g} / \mathrm{dl}(\mathrm{OR}=10.63 ; 95 \% \mathrm{CI}=1.36-13.3$; $\mathrm{p}=0.024$ ) (Table 4 ). The mortality rate was $17.5 \%$. In univariate analysis, hypertensive retinopathy $(\mathrm{OR}=4.04,95 \% \mathrm{CI}=1.58-10.32 ; \mathrm{p}=0.001), \mathrm{LVH}$ $(\mathrm{OR}=1.25,95 \% \mathrm{CI}=1.14-1.40 ; \mathrm{p}=0.015)$, stage 5 renal disease $(\mathrm{OR}=2.00$; $95 \% \mathrm{CI}=1.77-4.31 ; \mathrm{p}=0.0001)$, hemoglobin $<12 \mathrm{~g} / \mathrm{dl}(\mathrm{OR}=1.28,95 \% \mathrm{CI}=$ $1.15-1.43 ; \mathrm{p}=0.003)$ and hemoglobin $<8 \mathrm{~g} / \mathrm{dL}(\mathrm{OR}=2.25,95 \% \mathrm{CI}=1.05-4.8$; $\mathrm{p}=0.04$ ) were associated with death in our patients (Table 5); In multivariate analysis, stage 5 renal disease $(\mathrm{OR}=3.8,95 \% \mathrm{CI}=2.9-5.71 ; \mathrm{p}=0.001)$, stage 3 retinopathy $(\mathrm{OR}=5.36,95 \% \mathrm{CI}=1.81-15.84 ; \mathrm{p}=0.002)$ and hemoglobin $<8 \mathrm{~g} / \mathrm{dl}$ $(\mathrm{OR}=2.78 ; 95 \% \mathrm{CI}=1.03-7.49 ; \mathrm{p}=0.042)$ were associated with mortality (Table 5). The analysis of the survival curve according to the Cox regression model showed that stage 5 renal disease $(p=0.002)$ (Figure 3$)$, hemoglobin level < $8 \mathrm{~g} / \mathrm{dl}(\mathrm{p}=0.039)$ (Figure 4$)$ and hypertensive retinopathy $(\mathrm{p}=0.04)$ (Figure 5$)$ were associated with mortality.

\section{Discussion}

Our study aims to describe the profile of patients receiving multiple antihypertensive therapy in our conditions of practice. To this end, patients were included 


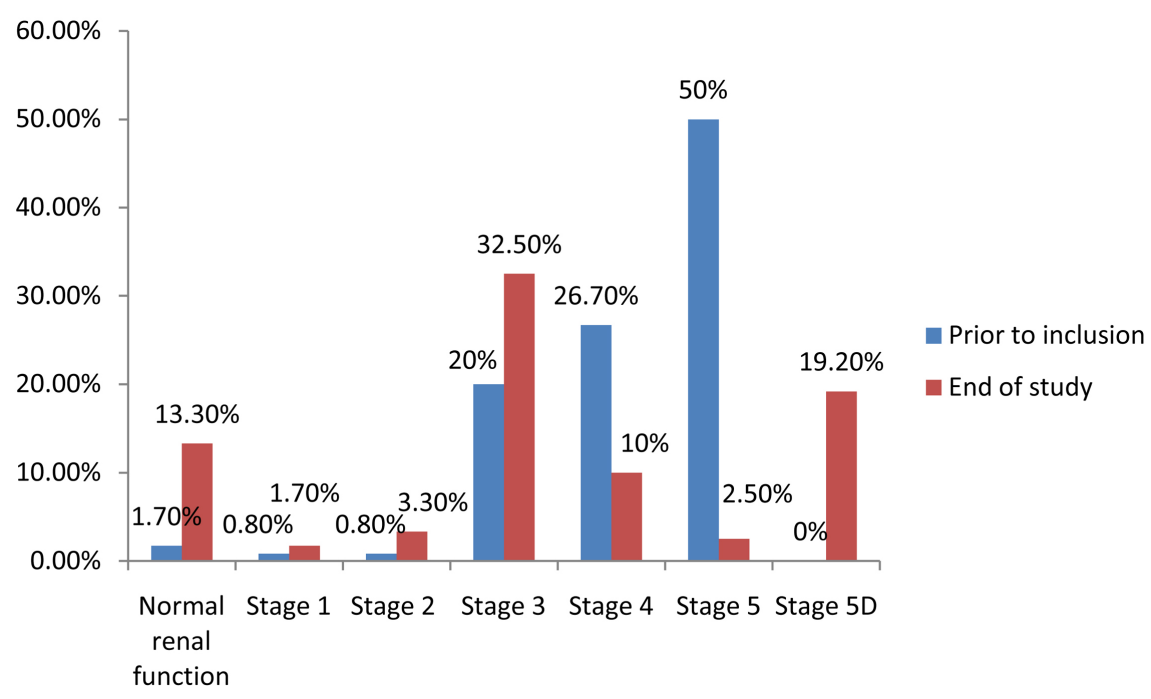

Figure 2. Renal disease stage progression.

Table 3. Combination therapy to reach target blood pressure.

\begin{tabular}{ccccc}
\hline \multicolumn{5}{c}{ Target Blood Pressure } \\
\hline Combination & Yes $(\mathrm{n}=77)$ & No $(\mathrm{n}=43)$ & P Value & OR 95\% CI \\
\hline CCB + D + ACEI + C & $32.5 \%(25 / 77)$ & $37.2 \%(16 / 43)$ & 0.37 & $0.92(0.69-1.24)$ \\
CCB + D + ARB + C & $11.7 \%(9 / 77)$ & $14 \%(6 / 43)$ & 0.46 & $0.92(0.59-1.43)$ \\
CCB + D + ACEI & $24.7 \%(19 / 77)$ & $20.9 \%(9 / 43)$ & 0.41 & $1.07(0.79-1.45)$ \\
CCB + D + ARB & $7.8 \%(6 / 77)$ & $14 \%(6 / 43)$ & 0.22 & $0.76(0.42-1.36)$ \\
Others & $23.4 \%(18 / 77)$ & $14 \%(6 / 43)$ & 0.15 & $1.22(0.92-1.61)$ \\
\hline
\end{tabular}

Table 4. Risk factors for progression of kidney disease in multivariate analysis.

\begin{tabular}{ccccc}
\hline & & & \multicolumn{2}{c}{$95 \%$ Confidence Interval } \\
\hline Variables & $\boldsymbol{P}_{\text {value }}$ & OR & Lower & Greater \\
\hline Stage 5 renal disease at inclusion & 0.0001 & 14.52 & 4.08 & 21.65 \\
Persistent hypertension & 0.0001 & 12.85 & 4.45 & 17.13 \\
Hemoglobin $<12 \mathrm{~g} / \mathrm{dl}$ & 0.024 & 10.63 & 1.36 & 13.3 \\
Retinopathy & 0.37 & - & - & - \\
\hline
\end{tabular}

during 10 months and each of them was followed up for 6 months. The limitations of the study are the small sample size and its monocentric nature. The 120 patients had complete data. This is sufficient for the overall analysis but insufficient for a more in-depth analysis of results. In spite of these limitations, the analysis yielded a few relevant results.

The prevalence of multiple antihypertensive therapy varies according to authors. It is around $19 \%$ to $21 \%$ in some series [12] [13] [14]. On the other hand, according to Olaurewaju et al., in Nigeria, it was 51.5\% [15]. In Wang et al. study, triple antihypertensive therapy accounted for $64.2 \%$ of their study population in China [16]. 
Table 5. Characteristics of patients according to outcomes.

\begin{tabular}{|c|c|c|c|c|}
\hline \multicolumn{5}{|c|}{ Death } \\
\hline & Yes $(n=21)$ & No $(n=99)$ & $P$ value & OR (95\%) \\
\hline Male & $57.1 \%(17 / 21)$ & $45.5 \%(45 / 99)$ & 0.51 & $1.01(0.85-1.20)$ \\
\hline Age $<35$ years & $33.3 \%(7 / 21)$ & $25.3 \%(25 / 99)$ & 0.30 & $1.37(0.61-3.09)$ \\
\hline [35 - 65] & $47.6 \%(10 / 21)$ & $64.6 \%(64 / 99)$ & 0.11 & $1.13(0.94-1.36)$ \\
\hline$\geq 65$ years & $19 \%(4 / 21)$ & $10.1 \%(10 / 99)$ & 0.20 & $1.78(0.69-4.54)$ \\
\hline Known Hypertension & $19 \%(4 / 21)$ & $23.2 \%(23 / 99)$ & 0.46 & $1.04(0.86-1.25)$ \\
\hline Diabetes & $14.3 \%(3 / 21)$ & $17.2 \%(17 / 99)$ & 0.51 & $0.96(0.78-1.18)$ \\
\hline Tobacco & $23.8 \%(5 / 21)$ & $24.2 \%(24 / 99)$ & 0.60 & $0.99(0.82-1.20)$ \\
\hline Obesity & $9.5 \%(2 / 21)$ & $5.1 \%(5 / 99)$ & 0.35 & $1.69(0.49-5.87)$ \\
\hline \multicolumn{5}{|l|}{ Hypertension grade } \\
\hline Normal BP & $0 \%$ & $2 \%(2 / 99)$ & 0.67 & $1.21(1.11-1.32)$ \\
\hline Grade 1 Hypertension & $0 \%$ & $2 \%(2 / 99)$ & 0.67 & $1.21(1.11-1.32)$ \\
\hline Grade 2 Hypertension & $23.8 \%(5 / 21)$ & $11.1 \%(11 / 99)$ & 0.11 & $2.03(0.86-4.77)$ \\
\hline Grade 3 Hypertension & $76.2 \%(16 / 21)$ & $84.8 \%(84 / 99)$ & 0.25 & $1.12(0.85-1.46)$ \\
\hline \multicolumn{5}{|l|}{ Renal disease stage } \\
\hline Normal & $0 \%$ & $4 \%(4 / 99)$ & 0.45 & $1.22(1.12-1.33)$ \\
\hline Stage 1 & $0 \%$ & $2 \%(2 / 99)$ & 0.67 & $1.21(1.11-1.32)$ \\
\hline Stage 2 & $0 \%$ & $1 \%(1 / 99)$ & 0.82 & $1.21(1.11-1.32)$ \\
\hline Stage 3 & $4.8 \%(1 / 21)$ & $23.2 \%(23 / 99)$ & 0.043 & $1.21(1.06-1.38)$ \\
\hline Stage 4 & $0 \%$ & $32.3 \%(32 / 99)$ & 0.001 & $1.31(1.16-1.47)$ \\
\hline Stage 5 & $95.2 \%(20 / 21)$ & $40.41 \%(40 / 99)$ & 0.0001 & $2.00(1.77-4.31)$ \\
\hline \multicolumn{5}{|l|}{$\begin{array}{l}\text { Hemoglobin level } \\
\text { (g/dl) }\end{array}$} \\
\hline$\geq 12$ & $0 \%$ & $26.3 \%(26 / 99)$ & 0.003 & $1.28(1.15-1.43)$ \\
\hline$[8-12]$ & $57.1 \%(12 / 21)$ & $52.5 \%(52 / 99)$ & 0.44 & $1.16(0.53-2.56)$ \\
\hline$<8$ & $42.9 \%(9 / 21)$ & $21.2 \%(21 / 99)$ & 0.04 & $2.25(1.05-4.80)$ \\
\hline \multicolumn{5}{|l|}{ Fundoscopic exam } \\
\hline Normal & $9.5 \%(2 / 21)$ & $35.4 \%(35 / 99)$ & 0.014 & $0.23(0.05-0.96)$ \\
\hline Retinopathy 1 & $0 \%$ & $6.1 \%(6 / 99)$ & 0.30 & $1.22(1.12-1.33)$ \\
\hline Retinopathy 2 & $14.3 \%(3 / 21)$ & $21.2 \%(21 / 99)$ & 0.35 & $1.07(0.90-1.28)$ \\
\hline Retinopathy 3 & $76.2 \%(16 / 21)$ & $37.4 \%(37 / 99)$ & 0.001 & $4.04(1.58-10.32)$ \\
\hline LVH & $100 \%(21 / 21)$ & $79.8 \%(79 / 99)$ & 0.015 & $1.26(1.14-1.40)$ \\
\hline \multicolumn{5}{|l|}{$\begin{array}{c}\text { Etiology of } \\
\text { hypertension }\end{array}$} \\
\hline Essential & $57.1 \%(12 / 21)$ & $60.6 \%(60 / 99)$ & 0.47 & $1.02(0.86-1.21)$ \\
\hline Chronic GN & $28.6 \%(6 / 21)$ & $24.2 \%(24 / 99)$ & 0.43 & $1.20(0.51-2.81)$ \\
\hline Diabetes & $14.3 \%(3 / 21)$ & $13.1 \%(13 / 99)$ & 0.56 & $1.08(0.35-3.26)$ \\
\hline PKD & $0 \%$ & $2 \%(2 / 99)$ & 0.67 & $1.21(1.11-1.32)$ \\
\hline
\end{tabular}

LVH = Left Ventricular Hypertrophy; GN = Glomerulonephritis; PKD = Polycystic Kidney Disease. 


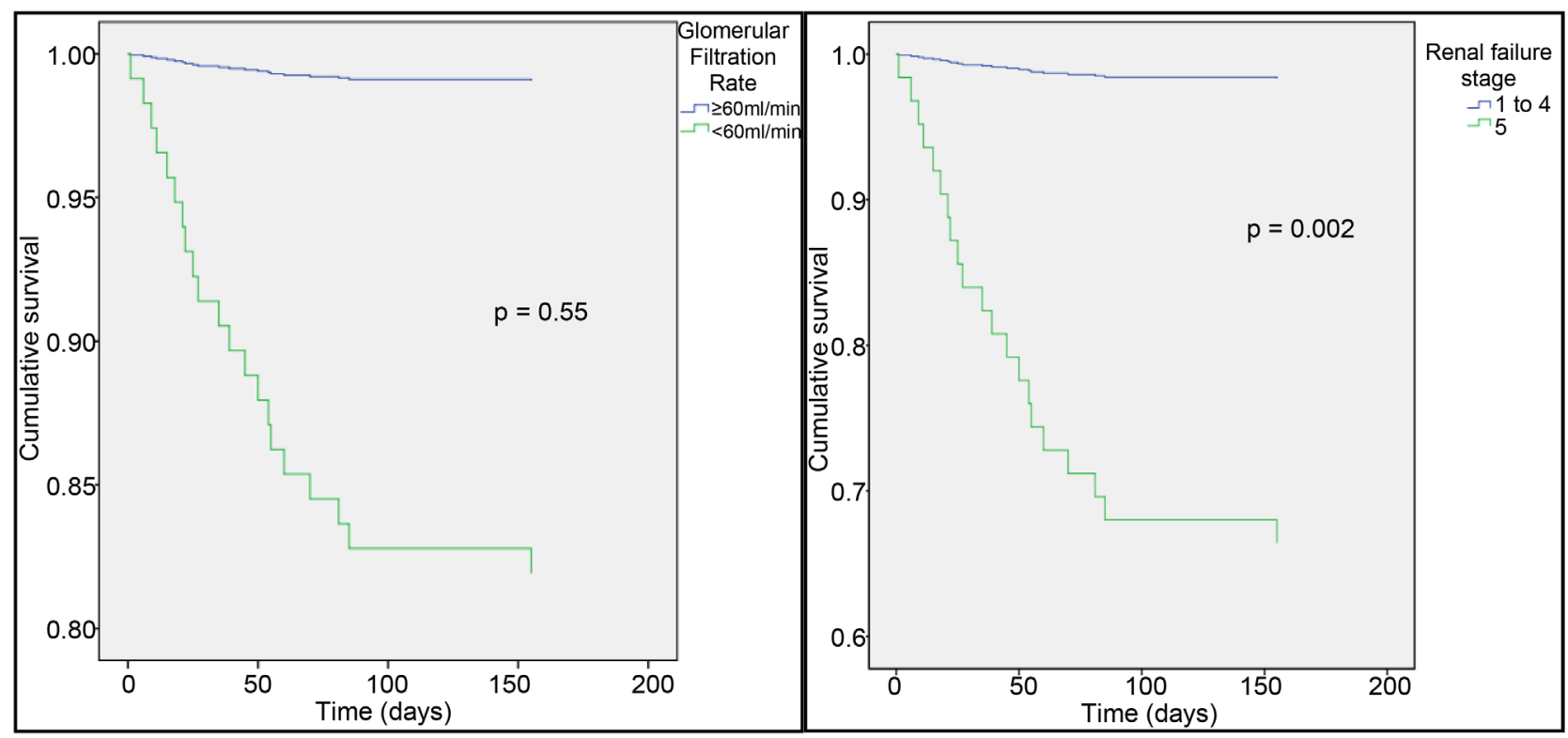

Figure 3. Cumulative survival according to glomerular filtration rate and renal failure stage.

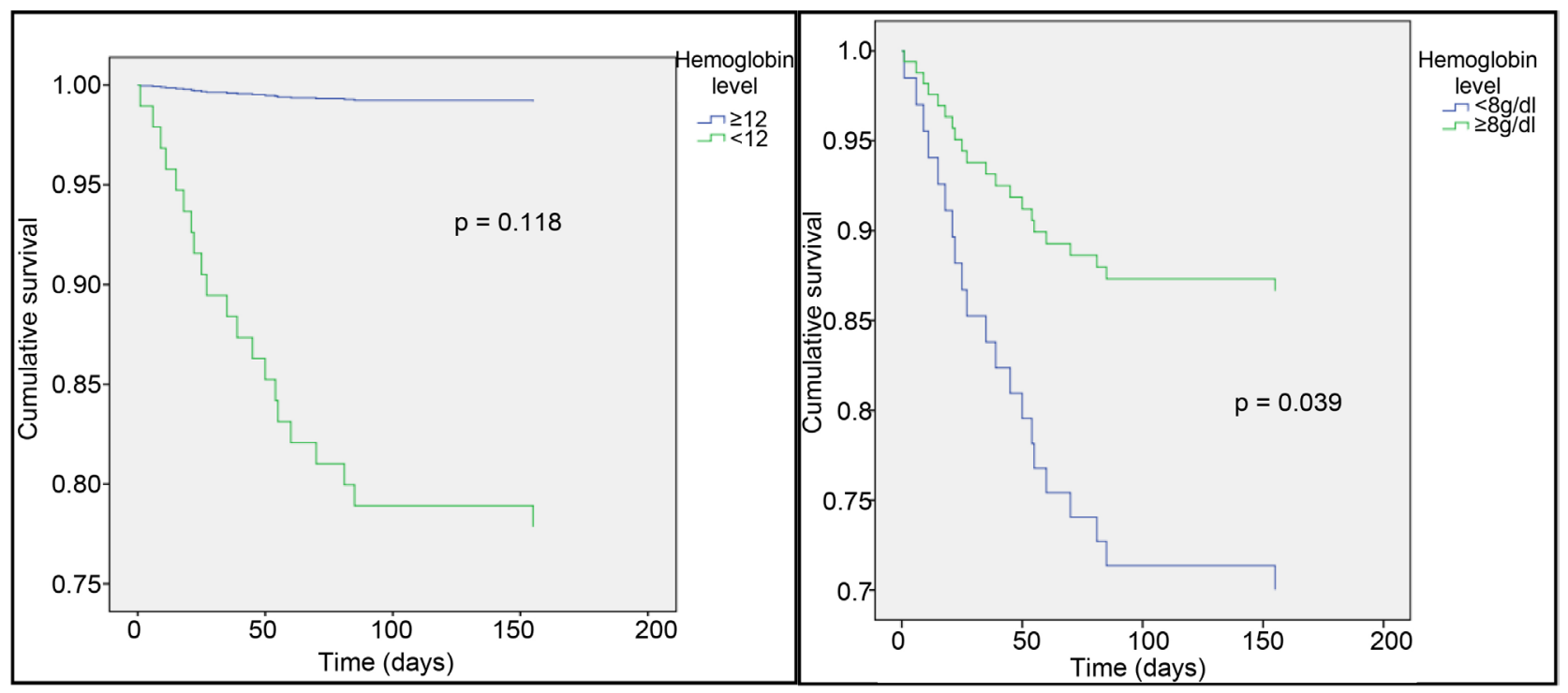

Figure 4. Cumulative survival according to hemoglobin level.

The young age of patients is reported in most studies conducted in Africa [13] [14]. The reported clinical signs are the expression of the multiple organ effects of hypertension (cardiac, renal). Almost all our patients already had an impaired renal function at first contact with the department. It looks as if impaired renal function is the only reason for nephrology referral. According to Anthony $\mathrm{J}$ et al., HT was secondary in $13 \%$ to $17 \%$ of adult patients (19 - 64 years) in the USA [17]. In our study, 2 out of 5 patients had secondary hypertension. This could be due to the substantial proportion of chronic glomerulonephritis in the young population like ours.

Various classes of drugs were combined in varying proportions. In most series, 


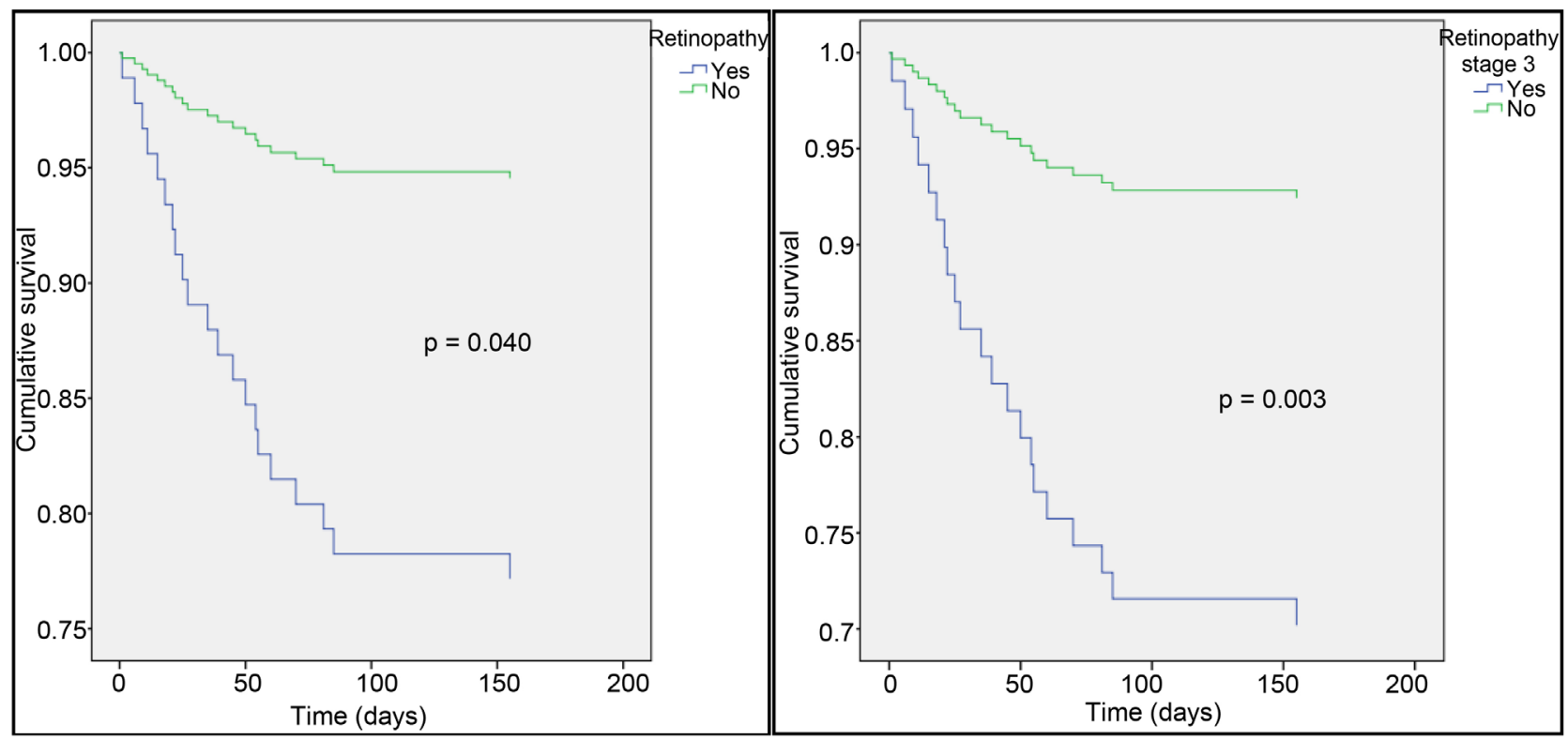

Figure 5. Cumulative survival according to hypertensive retinopathy and stage.

calcium channel blockers are the most commonly used classes, followed by ACEI and ARB in varying proportions [18] [19]. In Wang study, diuretics were the most commonly used drugs [16]. This multiple therapy is performed due to the severity of hypertension. It is thus not related to the etiology of HT. The guidelines suggest that the combination of one calcium channel blocker, one angiotensin receptor blocker (ARB) and one diuretic is the preferred combination when a multiple therapy is required [1]. In our context, we sometimes had to go beyond what is recommended by adding other molecules such as a centrally acting antihypertensive agent and/or a beta-blocker in order to achieve the target blood pressure.

We did not find any literature data on the relationship between the causes of HT and the combinations of antihypertensive drugs. In our study, over half of patients who received a combination of 5 antihypertensive drugs had an HT due to CGN. This non-significant difference could be related to the small number of patients in this group. A greater number would be useful in order to address this issue.

Mortality rate in our study is virtually identical to that found in other series [13]. Finally, the advanced stage of renal disease upon admission and failure to achieve the target blood pressure are factors for renal disease progression. This suggests a need for early consultation and a relatively rapid achievement of the target blood pressure to slow the progression of the disease. Conversely, retinopathy does not appear to be a factor for renal disease progression. However, hypertension has profound effects on various parts of the eye. Signs of hypertensive retinopathy are associated with other indicators of organic diseases (such as left ventricular hypertrophy and renal failure) and may be risk markers for future clinical events such as stroke, congestive heart failure and cardiovascular death [20] [21]. Furthermore, retinal microvascular abnormalities are associated 
with renal dysfunction, suggesting that common systemic microvascular processes may underlie the development of microvascular damages in the eyes and kidneys [22]. In the presence of chronic kidney disease, hypertensive retinopathy is a strong predictor of mortality [23].

Cardiovascular disease (CVD) and chronic kidney disease (CKD) often coexist and are known to have a bidirectional effect on one another [24]. CKD is a risk factor for the development of cardiovascular disease. Moreover, in patients with CVD, CKD is associated with a significantly increased risk of cardiovascular mortality [25]. The high proportion of renal failure in our hypertensive patients could thus explain this high mortality rate.

Anemia, often encountered in people with chronic diseases, is an additional mediator in the progression of chronic diseases, and also an independent risk factor for cardiovascular complications and mortality [26]. The prevalence of anemia increases with the advanced stage of CKD, as well as the mineral and bone disorders which increase the cardiovascular risk. Chronic kidney disease leads to an increased risk of mortality, which increases additively in the presence of anemia [27]. These findings suggest that early diagnosis and primary care management may be worth carrying out in this high-risk group.

\section{Conclusions}

Multiple antihypertensive therapy, which is common in nephrology, is related to the severity of HT and not to its cause. It enabled the normalization of blood pressure and the improvement of renal function in the majority of cases. However, mortality remains high and the factors associated with death are end-stage renal disease, stage 3 retinopathy and the presence of severe anemia.

Multiple antihypertensive therapy may pose the problem of treatment adherence due to the large number of drugs to be taken and patients' low socioeconomic status. Therapeutic education and the actual implementation of health insurance could be the key to good adherence to treatment, so as to prevent complications of hypertension or to slow down its progression.

\section{References}

[1] Blacher, J., Halami, J.-M., Hanon, O., Mourad, J.-J., Pathak, A., Schenebert, B. and Gired, X. (2013) Guidelines on the Management of Adult Hypertension, French Society of Hypertension. http://www.sfhta.eu/

[2] Couchoud, C., Lassalle, M. and Jacqueline, C. (2013) Report Rein 2011-Synthesis. Nephrologie \& Therapeutique, 9, S3-S6. https://doi.org/10.1016/S1769-7255(13)70036-1

[3] Ouattara, B., Kra, O., Yao, H., Kadjo, K. and Niamkey, E.K. (2011) Particularities of Chronic Renal Failure in Black Adult Patients Hospitalized in Internal Medicine of Treichville University Hospital. Nephrologie \& Therapeutique, 7, 531-534. https://doi.org/10.1016/j.nephro.2011.03.009

[4] Hannedouche, T. (2015) Hypertension and Kidney. Hypertension Magazine, 4, 5-7.

[5] World Health Organization-International Society of Hypertension Guidelines for the Management of Hypertension (1999) Guidelines Sub-Committee of the World 
Health Organization. Clinical and Experimental Hypertension, 21, 1009-1060.

[6] Abel, N., Contino, K., Jain, N., Grewal, N., Grand, E., Hagans, I., Hunter, K. and Roy, S. (2015) Eighth Joint National Committee (JNC-8) Guidelines and the Outpatient Management of Hypertension in the African-American Population. The American Journal of the Medical Sciences, 7, 438-445. https://doi.org/10.4103/1947-2714.168669

[7] American Diabetes Association (2015) Part2. Classification and Diagnosis of Diabetes. Diabetes Care, 38, S8-S16. https://doi.org/10.2337/dc15-S005

[8] National Kidney Foundation (2002) K/DOQI Clinical Practice Guidelines for Chronic Kidney Disease: Evaluation, Classification and Stratification. American Journal of Kidney Diseases, 39, S1-S266.

[9] KDIGO (2012) Clinical Practice Guideline for Glomerulonephritis. Kidney International, 2, 1-143.

[10] Standards of Medical Care (2011) Standards of Medical Care in Diabetes-2011. Diabetes Care, 34, S11-S61. https://doi.org/10.2337/dc11-S011

[11] Noël, N. and Rieu, P. (2015) Pathophysiology, Epidemiology, Clinical Presentation, Diagnosis and Treatment Options for Autosomal Dominant Polycystic Kidney Disease. Nephrologie \& Therapeutique, 11, 213-225.

[12] FLASH Survey 2009-2010 (2010). http://www.comitehta.org

[13] Yao, K.H., Sanogo, S., Binan, A.Y.O., Hue Lou, A. and Diallo, A.D. (2012) Complicated Novo Hypertension in Adults in Black African Hospital. Medecine d Afrique Noire, 59, 199-203.

[14] Koffi, J., N’Goran, Y., Bamba-kamagaté, D., N'Djessan, J.J. and Anzouan-Kacou, J.B. (2005) The Value of Therapeutic Education in Adherence to Antihypertensive Therapy in the Black Subject. The African Journal of the Thorax and Vessels, 32.

[15] Olanrewaju, T.O., Aderibigbe, A., Busari, O.A. and Sanya, E.O. (2010) Antihypertensive Drug Utilization and Conformity to Guidelines in a Sub-Saharan African Hypertensive Population. International Journal of Clinical Pharmacology and Therapeutics, 48, 68-75. https://doi.org/10.5414/CPP48068

[16] Wang, Z., Wang, X., Chen, Z., Wang, W., Zhu, H., Chen, W., Zhu, M., Hu, S., Staessen, J.A., Liu, L. and Fodor, J.G., Hypertension Control in Community Health Center Project Group (2014) Hypertension Control in Community Health Centers across China: Analysis of Antihypertensive Drug Treatment Patterns. American Journal of Hypertension, 27, 252-259. https://doi.org/10.1093/ajh/hpt186

[17] Viera, A.J. and Neutze, D.M. (2010) Diagnosis of Secondary Hypertension: An Age-Based Approach. American Family Physician, 82, 1471-1478.

[18] Ojji, D.B., Ajayi, S.O., Mamven, M.H., Alfa, J. and Albertino, D. (2013) Pattern of Prescription of Anti-Hypertensive Medications in a Tertiary Health Care Facility in Abuja, Nigeria. Ethnicity \& Disease, 23, 480-483.

[19] Xu, H., He, Y., Xu, L., Yan, X. and Dai, H. (2015) Trends and Patterns of Five Antihypertensive Drug Classes between 2007 and 2012 in China using Hospital Prescription Data. International Journal of Clinical Pharmacology and Therapeutics, 53, 430-437. https://doi.org/10.5414/CP202243

[20] Bhargava, M., Ikram, M.K. and Wong, T.Y. (2012) How Does Hypertension Affect Your Eyes? Journal of Human Hypertension, 26, 71-83. https://doi.org/10.1038/jhh.2011.37

[21] Grunwald, J.E., Ying, G.S., Maguire, M., Pistilli, M., Daniel, E., Alexander, J., Whittock-Martin, R., et al. (2012) Association between Retinopathy and Cardiovascular Disease in Patients with Chronic Kidney Disease (from the Chronic Renal Insuffi- 
ciency Cohort [CRIC] Study). American Journal of Cardiology, 110, 246-253.

[22] Wong, T.Y., Coresh, J., Klein, R., Muntner, P., Couper, D.J., Sharrett, A.R., Klein, B.E., Heiss, G., Hubbard, L.D. and Duncan, B.B. (2004) Retinal Microvascular Abnormalities and Renal Dysfunction: The Atherosclerosis Risk in Communities Study. Journal of the American Society of Nephrology, 15, 2469-2476. https://doi.org/10.1097/01.ASN.0000136133.28194.E4

[23] Ricardo, A.C., Grunwald, J.E., Parvathaneni, S., Goodin, S., Ching, A. and Lash, J.P. (2014) Retinopathy and CKD as Predictors of All-Cause and Cardiovascular Mortality: National Health and Nutrition Examination Survey (NHANES) 1988-1994. American Journal of Kidney Diseases, 64, 198-203. https://doi.org/10.1053/j.ajkd.2014.01.437

[24] Glynn, L.G., Reddan, D., Newell, J., Hinde, J., Buckley, B. and Murphy, A.W. (2007) Chronic Kidney Disease and Mortality and Morbidity among Patients with Established Cardiovascular Disease: A West of Ireland Community-Based Cohort Study. Nephrology Dialysis Transplantation, 22, 2586-2594. https://doi.org/10.1093/ndt/gfm222

[25] Horwich, T.B., Fonarow, G.C., Hamilton, M.A., MacLellan, W.R. and Borenstein, J. (2002) Anemia Is Associated with Worse Symptoms, Greater Impairment in Functional Capacity and a Significant Increase in Mortality in Patients with Advanced Heart Failure. Journal of the American College of Cardiology, 39, 1780-1786.

[26] Young, J.B., Abraham, W.T., Albert, N.M., Gattis Stough, W., Gheorghiade, M., Greenberg, B.H., O’Connor, C.M., She, L., Sun, J.L., Yancy, C.W., et al. (2008) Relation of Low Hemoglobin and Anemia to Morbidity and Mortality in Patients Hospitalized with Heart Failure (Insight from the OPTIMIZE-HF Registry). American Journal of Cardiology, 101, 223-230.

[27] Anderson, J., Glynn, L.G., Newell, J., Iglesias, A.A., Reddan, D. and Murphy, A.W. (2009) The Impact of Renal Insufficiency and Anaemia on Survival in Patients with Cardiovascular Disease: A Cohort Study. BMC Cardiovascular Disorders, 9, 51. https://doi.org/10.1186/1471-2261-9-51

Scientific Research Publishing

\section{Submit or recommend next manuscript to SCIRP and we will provide best service for you:}

Accepting pre-submission inquiries through Email, Facebook, LinkedIn, Twitter, etc. A wide selection of journals (inclusive of 9 subjects, more than 200 journals)

Providing 24-hour high-quality service

User-friendly online submission system

Fair and swift peer-review system

Efficient typesetting and proofreading procedure

Display of the result of downloads and visits, as well as the number of cited articles

Maximum dissemination of your research work

Submit your manuscript at: http://papersubmission.scirp.org/

Or contact ojneph@scirp.org 